\title{
Fingerprinting and quantification of lessivage
}

\author{
CARleTON R. BERN ${ }^{1}$
}

\section{${ }^{1}$ U.S. Geological Survey, Colorado Water Science Center,} Denver, Colorado (cbern@usgs.gov)

Lessivage is the physical dispersion and translocation of small mineral particles, particularly clays, from overlying to underlying soil horizons. The process is important to understanding pedogenesis but the clay-enriched, illuviated horizons also influence drainage, water-holding capacity, nutrient retention, and fate of contaminants in soils. Lessivage involves small and episodic fluxes that are difficult to measure, and its importance remains a subject of debate. Here, lessivage is quantified by using the dual phase mass balance model, which separates the mass balance of element gains and losses in soil into particulate and solutional components. Quantification is performed on Ulltisols (Kanhapludults) developed from granite of the Liberty Hill Pluton in the Piedmont of South Carolina, USA. Three types of data were needed for the quantification: elemental concentrations in soil, granite parent material, and waterdispersible mineral particles $<1 \mu \mathrm{m}$. The particles were dispersed from soil in the laboratory, centrifuged, and screened through $1 \mu \mathrm{m}$ mesh.

The poorly-soluble elements $\mathrm{Ti}$ and $\mathrm{Zr}$ have an enriched ratio $(\mathrm{Ti} / \mathrm{Zr})$ in the $<1 \mu \mathrm{m}$ particles. Vertical patterns of that ratio in the soil profiles fingerprint losses of fine particles from eluviated horizons and gains in illuviated horizons. Clay, predominantly kaolinite with minor illite quantified by $\mathrm{X}$-ray diffraction, is present in concentrations 7 to $70 \mathrm{wt}$ \% throughout the soil profiles from the surface to saprolite $7 \mathrm{~m}$ deep. Such ubiquity of clay in soil profiles has been one of the challenges to tracing lessivage, because it requires distinguishing translocated clay from that formed in situ. Quantification of particulate gains and losses of $\mathrm{Al}$ and $\mathrm{Fe}$ show losses only from $<0.3$ m-deep soil and gains generally between 0.3 and $1.6 \mathrm{~m}$, and reflect the eluviation and illuviation components of lessivage, respectively. Little to no particulate movement of $\mathrm{Al}$ and $\mathrm{Fe}$ are traced in the saprolite below $1.6 \mathrm{~m}$, demonstrating that lessivage is less active in saprolite. Translocation of other elements like $\mathrm{Cu}, \mathrm{Zn}, \mathrm{U}$, and the REEs show similar patterns to $\mathrm{Al}$ and $\mathrm{Fe}$, illustrating the importance of lessivage to their distibutions in soil. In contrast, more soluble and nutrient elements like $\mathrm{Ca}$ and $\mathrm{P}$ show losses not associated with $<1 \mu \mathrm{m}$ particles or lessivage. For a state factor perspective, lessivage in these Ultisols is compared to that quantified by the dual-phase model in two other settings with different climate and parent material. 